\title{
A new peculiar DNA structure: NMR solution structure of a DNA kissing complex
}

\author{
F. Barbault ${ }^{1}$, T. Huynh-Dinh ${ }^{2}$, J. Paoletti ${ }^{1}$ and G. Lancelot ${ }^{1 *}$ \\ 1. Centre de Biophysique Moleculaire, CNRS Rue C. Sadron, 45071 Orleans Cedex 02, France (affiliated to Orleans University) \\ 2. Laboratoire de Chimie Organique, Institut Pasteur, 28 rue du Docteur Roux, Paris 75724 Cedex 15, France \\ * Phone: 3302382555 71; Fax: 33023863 15 17; E-mail: lancelot@enrs.orleans.fr
}

\section{Original reference:}

F. Barbault, T. Huynh-Dinh, J. Paoletti, G. Lancelot Journal of Biomolecular Structure \& Dynamics, 2002 (19) 649-58

\begin{abstract}
The deoxyoligoribonucleotide d(CTTGCTGAAGCGCGCACGGCAAG) (dSL1) corresponding to the reverse transcripted sequence of the dimerization initiation site SL1 of HIV-1Lai RNA was synthesized using phosphoramidite chemistry. Like its oligoribonucleotide counterpart, dSL1 dimerized spontaneously in solution. Here we report the first NMR solution structure of a kissing complex formed with two DNA strands. The melting point of the DNA dimer $\left(35^{\circ} \mathrm{C}\right)$ was found slightly higher than the one of the corresponding RNA dimer $\left(32^{\circ} \mathrm{C}\right)$. Despite this only slight difference in melting point, several structural differences were observed between the ribo- and the deoxyribo- dimers. The solution structure of the deoxy- dimer was a symmetric homodimer with a loop-loop interaction stabilized by four central G-C base-pairs, a head to tail A-A base-pair arrangement between the A8 residues of the two strands and a stacking of $A 9$ with $\mathrm{C} 15$. As a consequence, $\mathrm{G} 10$ was not paired and occupied a position outside the stem and the loop. Each stem was formed by seven basepairs whose axis made an angle of about $100^{\circ}$ with the plane of the loops. The distortion of the helix at the junction of the stem and of the loop induced a fold up of the A8pA9 step with a phosphate-phosphate distance lowered to $4.5 \AA$. The plane of the non-canonical A-A basepair was oriented perpendicularly to the axis of the stems. The four central base-pairs formed an open fan-shaped motif with an angle of $20^{\circ}$ between the bases and each of them was oriented perpendicularly to the A8-A8 plane. The deviation of the computed chemical shifts and the experimental ones for the aromatic proton was always less than $0.25 \mathrm{ppm}$ for each of the 16 converged solution structures and their average less than $0.1 \mathrm{ppm}$.
\end{abstract}

\section{Introduction}

Hairpin structures formed in nucleic acids have received a considerable interest since they are implicated in important biological processes. However, if the RNA hairpins begin to be extensively known due to their implication in intra-RNA recognition processes (1-16) or in site specific interactions with numerous proteins with RNA (17), only little is known about the DNA hairpin structures.

Such structures are known as potential interaction sites for numerous proteins : topoisomerase II $(18,19)$, HIV-1 integrase (20) and SMC (21). The DNA hairpins could play also a role in some neurodegenerative diseases (22) by interfering with the DNA polymerase slippage (23).

Since in our laboratory, we had focused attention on hairpin structures and conformational changes associated with the dimerization of retroviral RNA, we became interested in checking if such types of structures were possible with deoxyribonucleotides since the proviral DNA contains on one strand sequences which are equivalent to those of the genomic RNA.

Our previous biochemical and NMR work together with many studies from other laboratories have shown that a sequence localized immediately upstream of the splice donor site inside the HIV-1 PsiRNA region is responsible for the dimerization initiation of the retroviral RNA. This 35 bases long sequence which is called SL1, is highly conserved and can adopt a stem loop structure which presents a complementary sequence in the loop. It has been shown that in vitro HIV-1 RNA dimer formation could be initiated by the annealing of the loop self-complementary sequence GCGCGC through a loop-loop recognition (13).

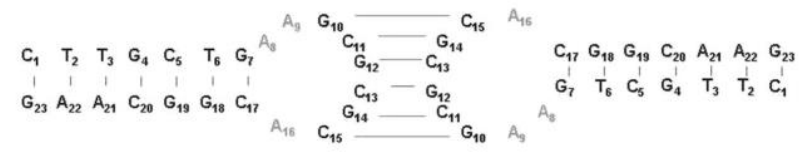

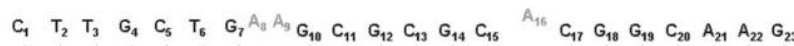

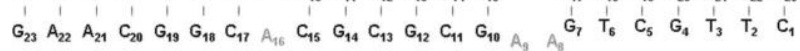

Figure 1: Tentative scheme of two possible conformations of the selfassociated dSL1: the kissing complex (top) and the extended duplex (below) on the basis of the two structures obtained with the dimer of SL1 HIV-1 wild type.

Along the dimerization process, this loop-loop duplex is converted either through temperature or through nucleocapside protein (14$16,24)$ into a more stable extended duplex. Structure of a kissing complex formed from a slightly mutated RNA fragment has already been proposed (25). Furthermore the solution structure of the extended duplex was elucidated (26) and a model corresponding to the transition from the loop-loop complex toward the extended duplex has been described in details (27) leading to the conclusion that the central stretches of G-C base pairs in the loop were kept associated during the transition.

Nevertheless, although the three dimensional solution structure was experimentally studied, the role played by the hydroxyl groups $2{ }^{\prime} \mathrm{OH}$ has never been investigated. Very recently, the analysis of a $10 \mathrm{~ns}$ dynamics trajectory including water molecules and carried out on a mutated SL1 RNA sequence where G12 has been substituted by A12 to prevent dimerization, indicated the formation of a stabilizing belt 
of hydrogen bonds between adjacent nucleotides both in the stem and the loop involving the 2 'OH groups (to be published).

In order to understand the implication of these $2^{\prime} \mathrm{OH}$ on the formation and the stabilization of a stem-loop structure together with the formation of a loop - loop duplex, we present here structural results obtained with 23 nucleotides long DNA sequence: C248 - G270 (dSL1).

The primary question was to know if such a sequence was able to form a stem-loop structure and furthermore to investigate if a DNA hairpin comprising a selfcomplementary sequence in the loop would be able to form a loop - loop duplex.

We present here the NMR solution structure of a loop - loop duplex obtained from SL1DNA sequence. This loop - loop structure presents several different features than the one obtained from equivalent SL1 RNA and these differences are discussed.

\section{Materials and Methods}

\section{Sample preparation and folding}

The 23-mer DNA (Figure 1) was synthesized on an automatic Millipore Expedite with the phosphoramidite chemistry. Two CPG columns of 15 micromoles were used. The DMT-on oligonucleotide was purified on reverse phase HPLC. After detritylation, the crude product was purified on HPLC, first with an ion-exchange (Waters DEAE-8HR) then with a reverse phase (Nucleosil 300-5C18) column. The total yield, after ion exchanging with Dowex-Na+, was $10.4 \%$ (23.5mg).

The sample was passed through a Chelex 100 column in order to remove the paramagnetic impurities for NMR experiments. The DNAsample was refolded by heating to $90^{\circ} \mathrm{C}$ during 3 minutes then snap-frozen at $4{ }^{\circ} \mathrm{C}$ for 4 minutes. The sample was concentrated by lyophilization and then dissolved in $90 \% \mathrm{H} 20$ / 10\% D20 or $100 \%$ D20 argon-degassed solution at a concentration of $2 \mathrm{mM}$ in a phosphate buffer $10 \mathrm{mM}$ at $\mathrm{pH}$ 5.8. An alternative protocol where the sample was folded by slow decreasing of the temperature to 90 to 4 ${ }^{\circ} \mathrm{C}$ led to NMR spectra of different features which will be published elsewere.

\section{NMR experiments}

NMR experiments were carried out on a Unity INOVA $600 \mathrm{MHz}$ spectrometer operating at 14.09 Tesla. Spectra were recorded with 300 and 1024 complex data points in the $\mathrm{t} 1$ and $\mathrm{t} 2$ dimensions. All D20 experiments water were carried out with the carrier frequency set on the HDO resonance, and a sweep width of $5997 \mathrm{~Hz}$ in the F1 and $\mathrm{F} 2$ dimensions. The residual $\mathrm{H} 2 \mathrm{O}$ resonance was irradiated by a weak presaturation during $1 \mathrm{~s}$. For experiments in $\mathrm{H} 2 \mathrm{O}$, a sweep width of $13000 \mathrm{~Hz}$ was used in the F1 and F2 dimensions. The watergate sequence (28) was used in order to remove the signal of water. Two-dimensional data sets for DQF-COSY, TOCSY and NOESY were recorded in the States mode. In D2O five NOESY spectra corresponding to $0,50,90,150$ and $300 \mathrm{~ms}$ mixing time were collected at $27^{\circ} \mathrm{C}$ with 32 scans for each $\mathrm{T} 1$ value and a recovery delay of $2 s$ without removing the sample or changing the gain. The t1 data were zero-filled to 2048 points and processed with a sine 90 phase shifted function. This apodization function does not distort the signal intensities, and the resulting peaks have no truncation effects. Correct phasing of the data in both dimensions was achieved with great care in order to quench the zero-quantum contribution in the cross-peak integration. The NOE values were obtained by dividing the volume of the cross-peak by the corresponding value of the diagonal obtained at $0 \mathrm{~ms}$ mixing time. The cross-peak volumes were calculated with integration routines of the VNMR software package. The 2D 1H-31P correlation spectra were recorded at $27{ }^{\circ} \mathrm{C}$ with 480 scans and with 48 and 1024 complex data points in the $\mathrm{t} 1$ and $\mathrm{t} 2$ dimensions, a sweep width of $5997 \mathrm{~Hz}$ and $800 \mathrm{~Hz}$ for $1 \mathrm{H}$ and $31 \mathrm{P}$ and a repetition time of $1 \mathrm{~s}$. All $1 \mathrm{H}$ and 31P spectra were referenced to the resonance from DSS and trimethylphosphate respectively.

\section{Results}

\section{Spectral assignments}

The NOE patterns for the stem region of dSL1 were consistent with those of a righthanded B-type helix. Figure 2 shows the NOESY spectra of the 23-mer DNA recorded in D2O. The seven $\mathrm{H} 5-\mathrm{H} 6$ connectivities as well as the three $\mathrm{CH} 3-\mathrm{H} 6$ connectivities observed on the TOCSY spectrum were good starting points for the sequential assignment. At $300 \mathrm{~ms}$ mixing time, all the $\mathrm{H} 6 / 8-\mathrm{H} 1^{\prime}, \mathrm{H} 6 / 8-\mathrm{H} 2^{\prime} / 2^{\prime \prime}$ and $\mathrm{H} 6 / 8-\mathrm{H} 6 / 8$ intra or inter connectivities were observed, leading to a total unambiguous sequential assignment at $27^{\circ} \mathrm{C}$. Figure 3 shows the NOESY spectra obtained at $120 \mathrm{~ms}$ mixing time in $\mathrm{H} 20$ : D2O $(90: 10)$ at $15^{\circ} \mathrm{C}$. The sequential assignment of the imino and amino protons in the stem was made directly and verified by comparison with the $\mathrm{H} 5-\mathrm{H} 6$ or $\mathrm{CH} 3-\mathrm{H} 6$ connectivities in $\mathrm{D} 20$. The assignment of the exchangeable protons of the 3 central G-C base-pairs was obtained starting to the $\mathrm{H} 5$ and $\mathrm{H} 6$ assigned resonances in D2O. No connectivity implying the exchangeable protons of $\mathrm{G} 10$ or $\mathrm{C} 15$ was observed for temperature between $4{ }^{\circ} \mathrm{C}$ and $40{ }^{\circ} \mathrm{C}$. A connectivity between $\mathrm{H} 8(\mathrm{~A} 8)$ and a $\mathrm{NH} 2$ resonance at $7.80 \mathrm{ppm}$ was observed. It was tentatively assigned to an amino proton of the adenine A8 or A9 or A16 since the amino groups of A21 and A22 were already assigned.

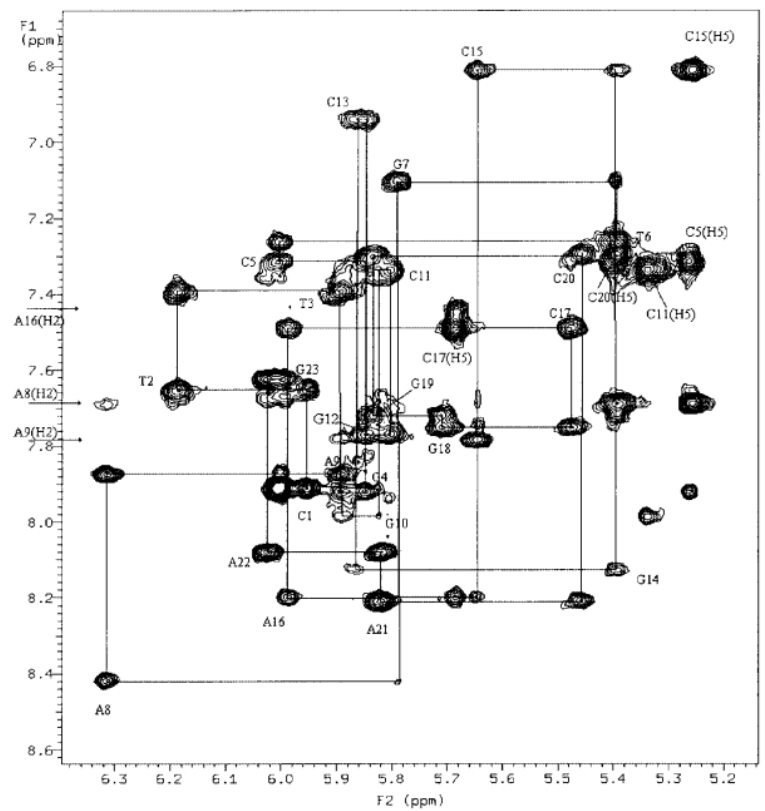

Figure 2: Expansion of the aromatic to H1' proton region of the NOESY spectrum of dSL1 dimer in D2O at $27^{\circ} \mathrm{C}$ obtained with a mixing time of $300 \mathrm{~ms}$. We can observe the very weak connectivity $\mathrm{H1}^{\prime}(\mathrm{G} 7)-\mathrm{H} 8(\mathrm{A8})$, the medium connectivities $\mathrm{H} 2(\mathrm{~A} 8)-\mathrm{H} 1^{\prime}(\mathrm{G} 14), \mathrm{H} 2(\mathrm{AB})-\mathrm{H} 5(\mathrm{C} 15)$ and $H 2(A 9)-H 6(C 15)$ and the lack of connectivity between H8(G14) and $H 5$ (C15). The arrows show the $H 2$ resonances of the adenines $A 8, A 9$ and $\mathrm{A} 16$.

\section{Usual and unusual NOEs}

Several special features were characteristic of the structure of this sequence in this conformation. The guanine of G10 as well as the cytosine of $\mathrm{C} 15$ were found unpaired. The observed NOE between $\mathrm{H} 8(\mathrm{~A} 8)$ and $\mathrm{NH} 2(\mathrm{~A} 8, \mathrm{~A} 9$ or $\mathrm{A} 16)$ suggested the presence of an A8-A8 or a $\mathrm{A} 9-\mathrm{A} 8$ or a $\mathrm{A} 16-\mathrm{A} 8$ base-pair since the distance between $\mathrm{H} 8$ and 
its own nearest amino proton $(4.9 \AA)$ is too large to induce a NOE of medium intensity. The high field chemical shift of the $\mathrm{H} 8$ (A8) proton $(8.42 \mathrm{ppm})$ reflected the lack of stacking for the five membered ring of the corresponding adenine. NOE data showed that the $\mathrm{H} 2$ of $\mathrm{A} 8$ was near to $\mathrm{H}^{\prime}{ }^{\prime}(\mathrm{G} 14), \mathrm{H} 5(\mathrm{C} 15)$ and that the $\mathrm{H} 2(\mathrm{~A} 9)$ was near to the $\mathrm{H} 1{ }^{\prime}(\mathrm{C} 15)$ although $\mathrm{A} 8$ and $\mathrm{A} 9$ are far away from $\mathrm{G} 14$ and $\mathrm{C} 15$ in the

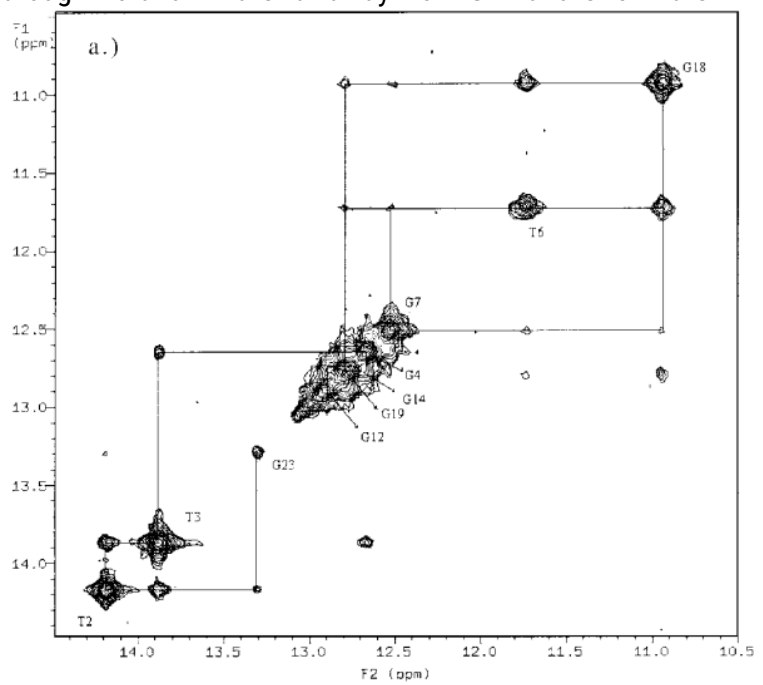

sequence. Moreover, $\mathrm{H} 2(\mathrm{~A} 8)$ was found near the $\mathrm{H} 8(\mathrm{G} 14)$ and the $\mathrm{H} 2$ (A16). The upfield chemical shift of $\mathrm{H6}(\mathrm{C} 15)$ as well as the NOEs $\mathrm{H} 6(\mathrm{C} 15)-\mathrm{H} 2(\mathrm{~A} 8)$ and $\mathrm{H6}(\mathrm{C} 15)-\mathrm{H} 2(\mathrm{~A} 9)$ suggested the stacking of $\mathrm{C} 15$ between $\mathrm{A} 8$ and $\mathrm{A} 9$.

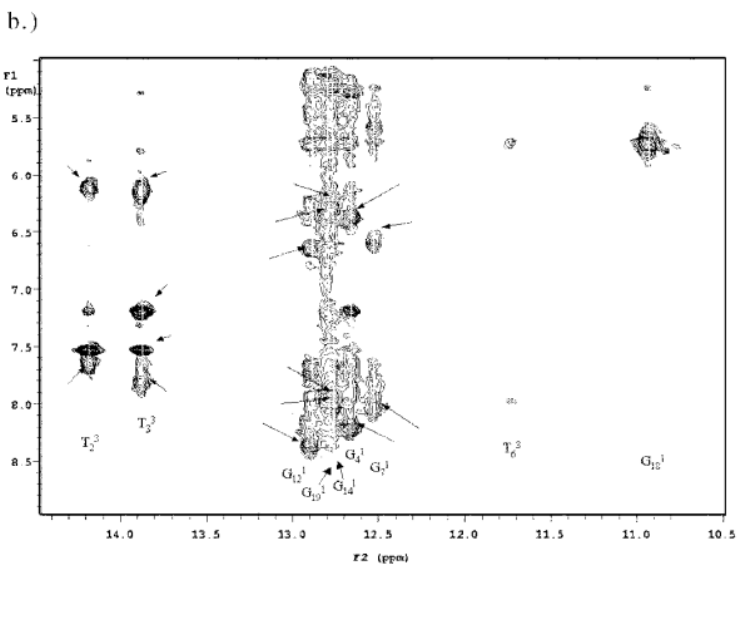

Figure 3: Portions of the $600 \mathrm{MHz}$ NOESY spectrum for the dSL1 dimer in H2O: D20 (90:10) solution at $05{ }^{\circ} \mathrm{C}$ obtained at $300 \mathrm{~ms}$ mixing time. a) connectivities between the imino protons $b$ ) connectivities between the imino protons and the aromatic or the amino protons.

\section{Duplex and backbone conformation}

The folding of dSL1 can be predicted from the NOESY and the COSYDQF data. Watson-Crick base-pairing, weak intensities of $\mathrm{H} 8 / 6(\mathrm{i})$ $\mathrm{H} 1^{\prime}(\mathrm{i})$, strong intensities of $\mathrm{H} 8 / 6(\mathrm{i})-\mathrm{H} 2^{\prime}(\mathrm{i})$ and predominately $\mathrm{C}^{\prime}$ endo sugar conformations all together indicate that the duplex, excepted A8, A9, G10, C15 and A16 presents a B-DNA helical structure. Moreover, the $1 \mathrm{H}-31 \mathrm{P}$ correlation spectrum of $\mathrm{dSL} 1$ shown in Figure 4, the majority of the resonances are concentrated in a narrow chemical-shift range of $1.0 \mathrm{ppm}$, a standard for regular helices. However, four resonances are found out of this range. Two of them correspond to G7pA8 and A8pA9 step and reflect the backbone distortion at the hinge between the stem base-pairs and the central basepairs. The two other resonances were assigned to C13pG14 and G14pC15.

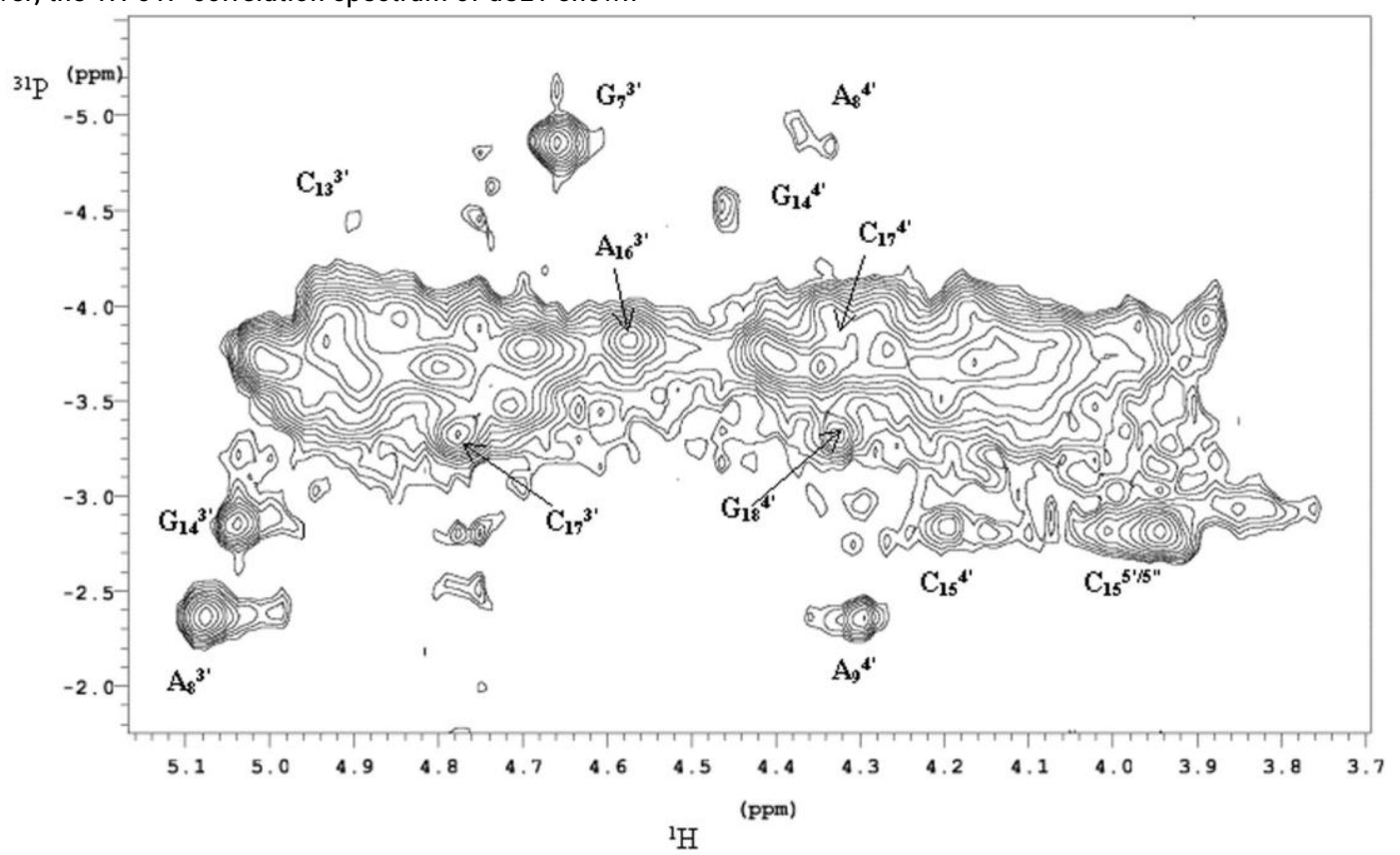

Figure $4:{ }^{31} \mathrm{P} H S Q C$ spectra of the $d S L 1$ dimer obtained at $27^{\circ} \mathrm{C}$. The connectivities of the ${ }^{31} \mathrm{P}$ resonances with $\mathrm{H} 3^{\prime}$ and $\mathrm{H}^{\prime}$ for the phosphorus $\mathrm{G} 7 \mathrm{pA} 8$, A8pA9, C15pA16, A16pC17 and C17pG18 are indicated.

\section{Structure determination}

\section{Experimental constraints}

Figure 5 shows a diagram summarizing the internucleotide NOE network observed for the residues $\mathrm{G} 7$ to $\mathrm{C} 17$ in the NOESY spectra of the DNASL1 dimer. Since evidence of chemical exchange between the same proton of the two strands was never observed in the NMR spectra, the same constraints were introduced for the corresponding nucleotides of each strands but the annealing process was never constrained to give a symmetrical structure. Atotal of 684 distance restraints, 258 dihedral restraints and 102 hydrogen bonding distances were used for the structure calculations (Table 1). This corresponds to 15 experimental constraints by residue. 
A C2'-endo conformation was assigned to all the ribose rings based on the $\mathrm{J}$ coupling constants observed on the DQF-COSY spectrum and was achieved by restraining their endocyclic torsion angles. For the other five backbone dihedral angles, a set of loose B-form helix restraints (B-form backbone $\pm 15^{\circ}$ ) were used to constrain the stem residues backbone ( $\mathrm{C} 1$ to $\mathrm{G} 7$ and $\mathrm{C} 17$ to $\mathrm{G} 23$ ) and the $\mathrm{C} 11-\mathrm{G} 14$ sequence to adopt a right helix conformation.

Table 1: NMR restraints and statistics for the dSL1 kissing complex. Data into brackets indicate values obtained with the $d S L 1$ extended duplex structures. (1) Geometric terms included bond, angle, improper, NOE and dihedral terms.(2) R.M.S.D : root mean square deviation in positions of heavy atoms compared to the global average structure.

\begin{tabular}{|c|c|c|}
\hline NMR restraints & & \\
\hline Distance restraints from $\mathrm{D}_{2} \mathrm{O}$ data & & \\
\hline Intra-residue & & 172 \\
\hline Inter-residue & & 322 \\
\hline Distance restraints from $\mathrm{H}_{2} \mathrm{O}$ data & & \\
\hline Waston-Crick base pairing & & 102 \\
\hline Exchangeable & & 88 \\
\hline Dihedral restraints & & \\
\hline Sugar pucker $\left(v_{1}, v_{2}, v_{3}\right)$ & & 138 \\
\hline Backbone & & 120 \\
\hline Total distance restraints & & 684 \\
\hline Force constant & & $50 \mathrm{kcal} \cdot \mathrm{mol}^{-1} \AA^{-2}$ \\
\hline Distance restraints per residue & & 14.9 \\
\hline Total dihedral restraints & & 258 \\
\hline Force constant & & $50 \mathrm{kcal} \cdot \mathrm{mol}^{-1} \cdot \mathrm{rad}^{-2}$ \\
\hline Dihedral restraints per residue & & 5.6 \\
\hline Total restraints & & 942 \\
\hline Distance and dihedral restraints per residue & & 20.5 \\
\hline Structural statistics & & \\
\hline Number of structures included & & (5) \\
\hline Energy & & \\
\hline All terms CHARMM force field calculation & $-613 \pm 70{\mathrm{kcal} . \mathrm{mol}^{-1}}^{-1}$ & $\left(+13819 \pm 1650 \mathrm{kcal} \mathrm{mol}^{-1}\right)$ \\
\hline Geometric terms $^{(1)}$ & $+309 \pm 47 \mathrm{kcal.mol}^{-1}$ & $\left(+11923 \pm 1270 \mathrm{kcal} \mathrm{mol}^{-1}\right)$ \\
\hline Van der Waals term & $-531 \pm 18{\mathrm{kcal} . \mathrm{mol}^{-1}}^{-1}$ & $\left(+2172 \pm 512 \mathrm{kcal} \mathrm{mol}^{-1}\right)$ \\
\hline Electrostatic term & $-391 \pm 25 \mathrm{kcal} \cdot \mathrm{mol}^{-1}$ & $\left(-276 \pm 7 \mathrm{kcal} \mathrm{mol}^{-1}\right)$ \\
\hline NMR constraints violation & & \\
\hline Number of distance violation up to $0.5 \AA$ & & $(27 \pm 4)$ \\
\hline Number of distance violation up to $0.3 \AA$ & & $3 \pm 2(105 \pm 7)$ \\
\hline Number of dihedral violation up to $5^{\circ}$ & & $0 \quad(4 \pm 2)$ \\
\hline R.M.S.D ${ }^{(2)}$ & & \\
\hline Stem 1 (bases:1-7;17-23) & & $0.44 \pm 0.17 \AA(9.2 \pm 2.8 \AA)$ \\
\hline Stem 2 (bases: $1^{\prime}-7^{\prime} ; 17^{\prime}-23$ ) & & $0.41 \pm 0.20 \AA(8.1 \pm 1.9 \AA)$ \\
\hline Middle stem (bases:11-14;11'-14) & & $0.32 \pm 0.11 \AA(2.3 \pm 0.7 \AA)$ \\
\hline Junctional bases $\left(8,9,10,15,16 ; 8^{\prime}, 9^{\prime}, 10^{\prime}, 15^{\prime}, 16^{\prime}\right)$ & & $1.11 \pm 0.35 \AA(7.7 \pm 1.3 \AA)$ \\
\hline Whole duplexe & & $1.72 \pm 0.58 \AA(10.5 \pm 2.8 \AA)$ \\
\hline
\end{tabular}

\section{Structure}

It has been shown that the RNA SL1 exists under two conformations in solution: the kissing complex and the extended form (25-27). It is not possible to discriminate between these forms on the basis of qualitative NOE data only. Thus, molecular dynamics calculations were undertaken with two methods in order to distinguish between the two types of associations (Figure 1). The first method fixed a linear duplex form i.e. pairing $\mathrm{C} 1$ with $\mathrm{G} 23$ of the other strand, pairing $\mathrm{C} 11$ with $\mathrm{G} 14$ of the other strand and so on. The second way fixed a kissing complex conformation, i.e. the pairing of $\mathrm{C} 1$ with $\mathrm{G} 23$ of the same strand, the pairing of C11 with G14 of the other strand and so on. The choice between the two conformations was made on the basis of the NOE energy and more importantly on the number of distance violations implicating the residues $A 8, A 9, G 10, C 15$ and A16.

In both cases, one hundred random structures were generated using CNS 1.0 (29). These basic starting structures were subjected to a simulated annealing-restrained molecular dynamic protocol in torsion angle space with a force-field consisting of bond lengths, bond angles, improper angles, repulsive van der Waals potential (single quartic repulsion), experimental distances and dihedral angles constraints from the NMR data (30). The force constants were imposed to be $50 \mathrm{Kcal} . \mathrm{mol}-1 . \AA^{-2}$ for all distances and 50 $\mathrm{Kcal} . \mathrm{mol}^{-1} \cdot \mathrm{rad}^{-2}$ for dihedral terms. The electrostatic terms were not present during the simulated annealing. Very close non-bonded contacts were first removed by 200 steps of Powell minimization (31). Initial velocities were assigned according to a Maxwell distribution at $20000 \mathrm{~K}$. Then an equilibration period consisted in $15 \mathrm{ps}$ dynamics in torsion angle space at $20000 \mathrm{~K}$ with a Van der Waals scale factor of 0.1 . The first cooling stage consisted in $75 \mathrm{ps}$ dynamics in torsion angle space where the temperature was cooled down from $20000 \mathrm{~K}$ to $0 \mathrm{~K}$ with the Van der Waals scale factor increased from 0.1 to 1 . This protocol was followed by a second cooling stage which consists in 80 ps dynamics in cartesian space where the temperature was cooled down from $2000 \mathrm{~K}$ to $0 \mathrm{~K}$ and where the Van der Waals scale factor increased from 1 to 4 . This protocol was finally followed by 1000 steps of Powell minimization with full electrostatic and Van der Waals terms. At this point, the converged structures were selected on the basis of their low NOE violations and their total energies. Finally, the structure convergence was examined graphically.

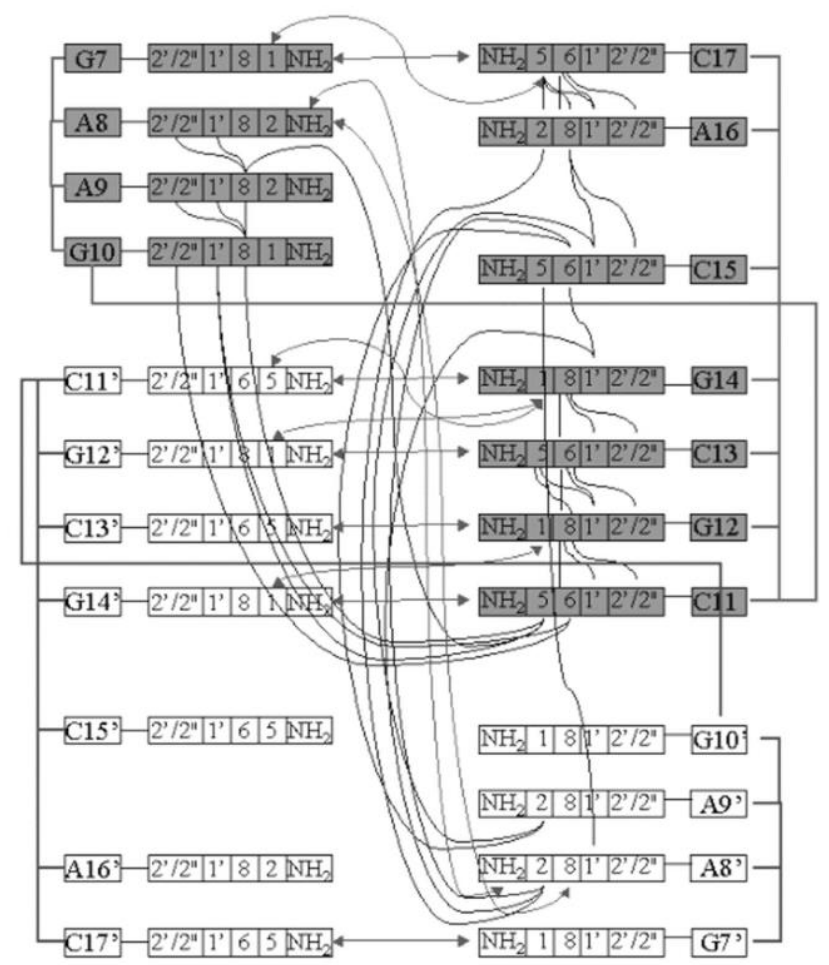

Figure 5: Summary of the distance restraints for the sequence G7-C17 / G7'-C17'. The observed interstrand restraints between the protons of the residues $A 8$ and $A 8$ ', $A 9$ and $C 11$ as well as the intrastrand connectivities between the non adjacent $A 8$ and $A 9$ with $C 15$ or $A 16$ residues are indicated.

\section{Loop-loop interaction in the dimer}

The global average structure of the 16 structures consisted in a symmetric homodimer (Figure 6) in which both SL1 whole stems (C1 to $\mathrm{G} 7$ and $\mathrm{C} 17$ to G23) form canonical B-type helix. The loop-loop interaction was stabilized by four Watson-Crick base-paires involving bases of the strands C11-G14 and G12-C13. The stemloop junctions were stabilized by head to tail A-A base-pairs involving two N6HN7 hydrogen bonds, a hydrogen bond between $\mathrm{N} 6 \mathrm{H}(\mathrm{A} 9)$ and $\mathrm{N} 3(\mathrm{~A} 8)$ of the same strands and a stacking of the adenine $A 9$ with $\mathrm{C} 15$ of the other strand. All the attempts to introduce a H8(A8)-NH2(A9 or A16) restraint failed whereas the distance between $\mathrm{H} 8(\mathrm{~A} 8)$ of a strand and $\mathrm{NH} 2(\mathrm{~A} 8)$ of the other strand was found $3.4 \AA$ even if this restraint is not specifically introduced. The guanine of $\mathrm{G} 10$ was found unpaired and out of the loops as already suggested by the lack of upfield shift of its $\mathrm{H} 8$ resonance. All the attempts to paired 
$\mathrm{G} 10$ and $\mathrm{C} 15$ lead to substantial violations of several restraints. The distortion of the helix conformation at the hinge of the stem and the loop induced a fold up of the A8pA9 backbone through a gauche+ gauche- transition of $\gamma(\mathrm{A} 8)$ and a phosphate-phosphate distance of $4.5 \AA$. The plane of the two paired adenines $A 8$ was perpendicular to the axis of the stems. The planes of the central G-C base-pairs were perpendicular to the axis of the stems and of the planes of the adenines $\mathrm{A} 8$. The whole of the four $\mathrm{G}-\mathrm{C}$ central pairs made a motif in open fan-shaped with an angle of 20 degrees between each plane, each plane been perpendicular to the A8-A8 plane (Figure 7).
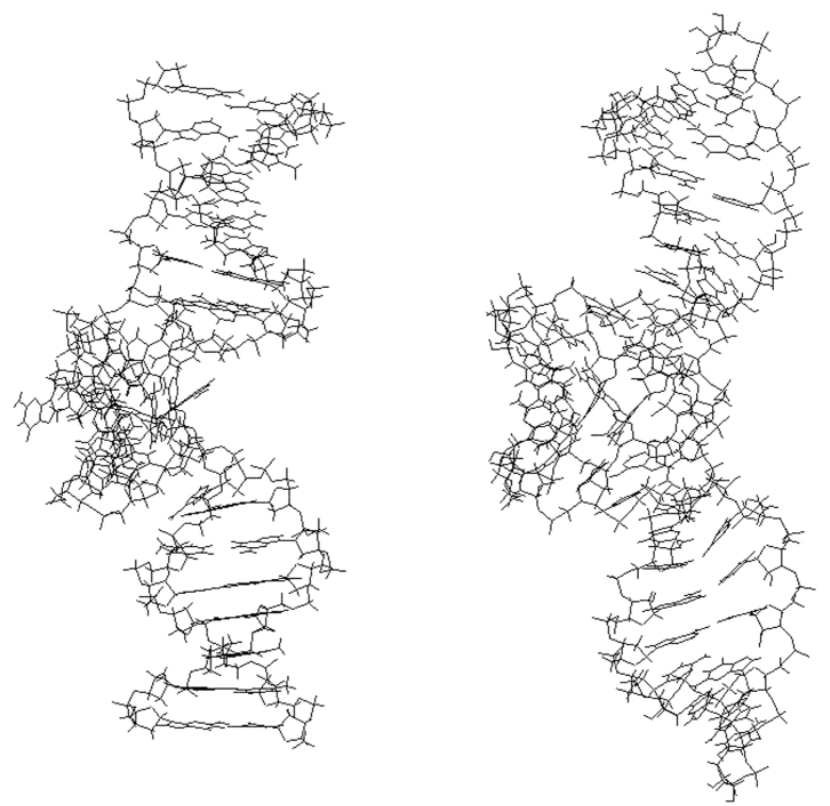

Figure 6: Global view of the kissing complexes of dSL1 (left) and of the RNA type of SL1 HIV-1Lai from Mujeeb et al (25), PDB accession number 1 bau(right).
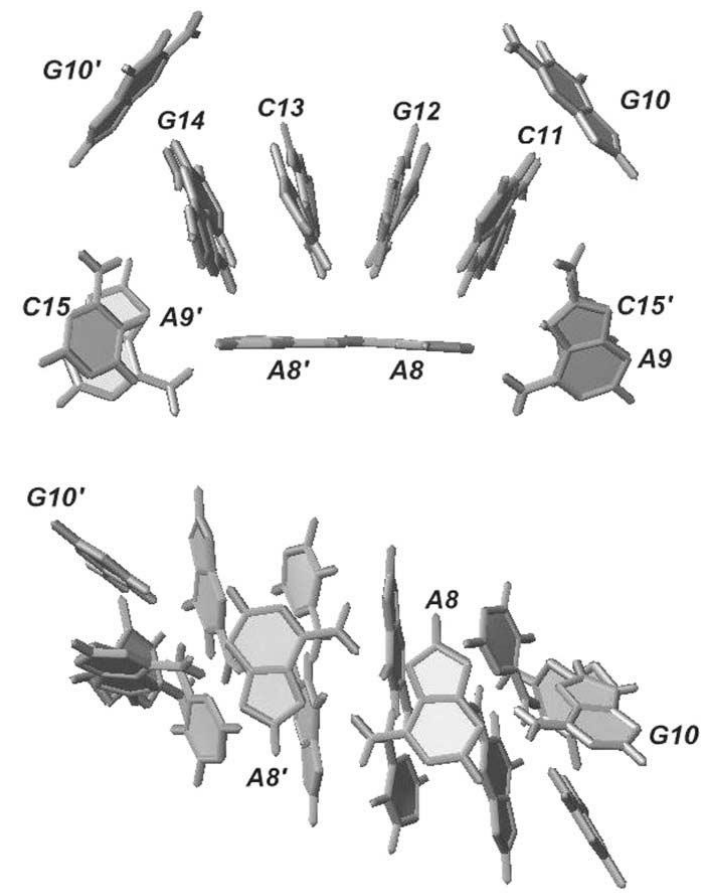

Figure 7: Two orthogonal views of the A8 to $\mathrm{C} 15$ residues in the metastable kissing complex. The axis of the two stems are perpendicularly to the plane of the figure. The planes of the four central G-C base-pairs and of the two adenines A8 are perpendicularly to the figure. This motif is centered in the middle of the oligonucleotide, symmetrically to the edges. The noncanonical A8-A8' base pair, the stacking of $A 9$ and $\mathrm{C}^{\prime} 5^{\prime}$ of the same strands and the unstacked $\mathrm{G} 10$ residues as well as their orientations are well visible. In order to clarify the figure, the planes of the bases are only shown and the base pairs G14-C11', C13-G12', G12-C13' and C11-G14' are noted $\mathrm{G} 14, \mathrm{C} 13, \mathrm{G} 12$ and $\mathrm{C} 11$ respectively.

\section{Test of the structure by back calculation of the chemical shifts}

The 16 converged structures were tested by comparing the computed chemical shifts of the $1 \mathrm{H}$ resonances by running NUCHEMICS (32) on each structure and the experimental ones. The maximum deviations of the computed chemical shifts from the experimental ones were $0.25,0.20,0.20 \mathrm{ppm}$ for the class of resonances $(\mathrm{H} 6, \mathrm{H} 8),(\mathrm{H} 2, \mathrm{H} 5, \mathrm{CH} 3)$ and $\mathrm{H}^{\prime}$ ' respectively. The corresponding average of the absolute value deviations were always less to $0.1,0.06$ and $0.08 \mathrm{ppm}$ respectively. Moreover the chemical shift deviations of the resonances belonging to residues whose special surrounding induced strong upfield shifts such as $\mathrm{H} 8(\mathrm{G} 7)(1.01 \mathrm{ppm}), \mathrm{H} 8(\mathrm{~A} 9)(0.63 \mathrm{ppm}), \mathrm{H} 6(\mathrm{C} 13)(0.89 \mathrm{ppm}), \mathrm{H} 2$ of all the adenines $(0.82$ to $1.23 \mathrm{ppm}), \mathrm{H} 1^{\prime}(\mathrm{A} 8)(1.12 \mathrm{ppm})$ were not higher than the others. We conclude that the special features of the unstable dimer of dSL1 were well represented by the 16 converged structures where only four G-C central base-pairs were observed. This last feature is a good test of the validity of our structure.

\section{Comparison with the SL1 RNA kissing complex structure}

The global average structures of both RNA and DNA of the SL1 kissing complexes in solution were a symmetric homodimer with loop-loop interaction. In both molecules, the structures of the kissing complexes are bent (about $100^{\circ}$ between the axis of the stem and the plane of the loop) and metastable. Their interfaces were formed not only by standard base pairing between palindromes, but also by a distinctive pattern of interstrand interactions at the stem-loop junctions. The backbone of the residues $\mathrm{A} 9-\mathrm{C} 17$ has the shape of a nearly planar $\mathrm{U}$ with slightly convergent ends. Each loop is deflected toward the major groove of its own stem, and the stems converge toward the major groove of the helix. In both cases, the structure is marked by abrupt discontinuities of stacking and by several unpaired junctional bases because the defect of self-complementary in this region. Nevertheless, several differences between the structural features of the two kissing complexes can be pointed out. Kissing complex formation of RNA SL1 induced a distortion of the loop helix junction and ruptured the distal G7-C17 base-pair of end stem while in the DNA sequence the $\mathrm{G} 7$ is Watson-Crick paired with $\mathrm{C} 17$. On the other hand, in RNA the six central G-C base pairs are present in the looploop interaction whereas only four of the central base pairs are formed with the DNAsequence. Moreover in the DNA, the A8 residues of the two strands are hydrogen bonded while in the RNA the three adenines formed a pair of interloop triple-base arrays (A8A9-C17) which are assumed to be critical for stabilizing the kissing complex. Consequently, in dSL1 the adenine of A9 was stacked with $\mathrm{C} 15$ in the same strand and the guanine of $\mathrm{G} 10$ was excluded of the stem and of the loop-loop motif. In RNA, A9 crossed the interface of its strand to stack with the $\mathrm{A} 8$ and $\mathrm{C} 17$ of the other strand. In the solution structure, this motif is found stabilized by an hydrogen bond between $05^{\prime}(\mathrm{A} 9)$ and $2^{\prime} \mathrm{OH}(\mathrm{A} 8)$. On the other hand, the stems of the RNA and DNA were found near to canonical A-helix and B-helix as generally observed for RNA and DNA, respectively. Despite these differences, the stability of the RNA and DNAkissing complex were about the same (melting temperatures of $32{ }^{\circ} \mathrm{C}$ and $35{ }^{\circ} \mathrm{C}$, respectively).

It can be pointed out that adenines are always present at the stemloop junction and in the loop of different SL1 isolates (33). For example, three adenines (A8, A9 and A16) are present in the SL1 of Lai isolate, and two adenines and one guanine in the SL1 Mal isolate. In the kissing complex of SL1Lai, A8 and A9 are implied in a 
triple base stacking with $\mathrm{C} 17$ of the other strand (25). In SL1Mal, the two adenines $\mathrm{A} 8$ and $\mathrm{A} 16$ were found in close proximity (34) suggesting a triple base-pair between bases of the two strands (33). In the extended duplex of SL1Lai, the three adenines A8, A9 and A16 form a zipper like motif involving the two strands of the duplex. In the metastable kissing complex of dSL1Lai, the adenines A8 of the two strands are paired and A9 is strongly stacked with $\mathrm{C} 15$. Although these adenines are implied in each case in different motifs, they are always participating as stabilizing factors of the two strand interaction. We conclude that, independently of the ribose or deoxyribose nature of the nucleic acid, the conserved adenines in the stem-loop junction play a key role in stabilizing the association of the strands.

Other factors such as hydrogen bonds involving the 2 ' $\mathrm{OH}$ hydroxyl groups in RNA, and bridges with water molecules can be important for stabilization but have not been investigated since the exchangeable $\mathrm{OH}$ resonances were not detected by NMR. Actually, dynamics molecular trajectories of the RNA kissing complex are run in order to study the stabilizing role of the $2{ }^{\prime} \mathrm{OH}$ groups. Results will be published later on.

\section{Coordinates}

The PDB accession number for this structure is 1JU0

\section{Acknowledgements}

This work was supported by a grant to J. Paoletti from Agence Nationale de la recherche sur le Sida (ANRS). F. Barbault was supported by the Ministère de l'Education Nationale, de la Recherche et de la Technologie.

\section{Supplementary Material}

This manuscript contains supplementary material. Table $\mathbf{S 1}$, is available at www.jbsdonline.com

\section{References and Footnotes}

Eguchi Y., Itoh T., and Tomizawa J. Annu Rev Biochem 60, 631-652 (1991).

Tomizawa J. Cell 38, 861-870 (1984).

Tomizawa J., and Som T. Cell 38, 871-878 (1984).

Tomizawa J. Cell 40, 527-535 (1985).

Tomizawa J. Cell 47, 89-97 (1986).

Tomizawa J. J Mol Biol 212, 683-694 (1990).

Coffin J. M. (1984) (Weiss, R., Teich, N., Varmus, H., and Coffin, J., Eds.) pp 261-

368 , Cold Spring Harbor, New York.

8. Bender W., and Davidson N. Cell 7, 595-607 (1976).

9. Temin H. M. Proc Natl Acad Sci U S A 90, 6900-6903 (1993)

10. Bieth E., Gabus C., and Darlix J. L. Nucleic Acids Res 18, 119-127 (1990).

11. Paillart J. C., Marquet R., Skripkin E., Ehresmann B., and Ehresmann C. J Biol Chem 269, 27486-27493 (1994).

12. Darlix J. L., Lapadat-Tapolsky M., de Rocquigny H., and Roques B. P. J Mol Biol 254, 523-537 (1995).

13. Muriaux D., Girard P. M., Bonnet-Mathoniere B., and Paoletti J. J Biol Chem 270, 8209-8216 (1995).

14. Laughrea M., and Jette L. Biochemistry 35, 9366-9374 (1996).

15. Laughrea M., and Jette L. Biochemistry 35, 1589-1598 (1996).

16. Muriaux D., Fosse P., and Paoletti J. Biochemistry 35, 5075-5082 (1996).

17. Gold L., Brown D., He Y., Shtatland T., Singer B. S., and Wu Y. Proc Natl Acad Sci U S A 94, 59-64 (1997).

18. Amir-Aslani A., Mauffret O., Bittoun P., Sourgen F., Monnot M., Lescot E., and Fermandjian S. Nucleic Acids Res 23, 3850-3857 (1995).

19. El Amri C., Mauffret O., Monnot M., Tevanian G., Lescot E., Porumb H., and Fermandjian S. J Mol Biol 294, 427-442 (1999).

20. Katz R. A., Gravuer K., and Skalka A. M. J Biol Chem 273, 24190-24195 (1998).

21. Connelly J. C., Kirkham L. A., and Leach D. R. Proc Natl Acad Sci U S A 95, 79697974 (1998).

22. McMurray C. T. Proc Natl Acad Sci U S A 96, 1823-1825 (1999).

23. Gacy A. M., Goellner G., Juranic N., Macura S., and McMurray C. T. Cell 81, 533540 (1995).

24. Muriaux D., De Rocquigny H., Roques B. P., and Paoletti J. J Biol Chem 271, 33686-33692 (1996).

25. Mujeeb A., Clever J. L., Billeci T. M., James T. L., and Parslow T. G. Nat Struct Biol 5, $432-436$ (1998)
26. Girard F., Barbault F., Gouyette C., Huynh-Dinh T., Paoletti J., and Lancelot G. J Biomol Struct Dyn 16, 1145-1157 (1999).

27. Theilleux-Delalande V., Girard F., Huynh-Dinh T., Lancelot G., and Paoletti J. Eur J Biochem 267, 2711-2719 (2000)

28. Piotto M., Saudek V., and Sklenar V. J Biomol NMR 2, 661-665 (1992).

29. Brunger A. T., Adams P. D., Clore G. M., DeLano W. L., Gros P., Grosse-Kunstleve R. W., Jiang J. S., Kuszewski J., Nilges M., Pannu N. S., Read R. J., Rice L. M., Simonson T., and Warren G. L. Acta Crystallogr D Biol Crystallogr 54, 905-921 (1998).

30. Stein E. G., Rice L. M., and Brunger A. T. J Magn Reson 124, 154-164 (1997).

31. Powell M. J. D. Mathematical Programming 12, 241-254 (1977)

32. Wijmenga S. S., Kruithof M., and Hilbers C. W. J Biomol NMR 10, 337 (1997).

33. Paillart J. C., Westhof E., Ehresmann C., Ehresmann B., and Marquet R. J Mol Biol 270, 36-49 (1997).

34. Dardel F., Marquet R., Ehresmann C., Ehresmann B., and Blanquet S. Nucleic Acids Res 26, 3567-3571 (1998). 